\title{
Respiratory involvements among women exposed to the smoke of traditional biomass fuel and gas fuel in a district of Bangladesh
}

\author{
Md. Abdul Alim • Mohammad Abul Bashar Sarker • \\ Shahjada Selim • Md. Rizwanul Karim • \\ Yoshitoku Yoshida $\cdot$ Nobuyuki Hamajima
}

Received: 8 July 2013/Accepted: 24 September 2013/Published online: 9 October 2013

(C) The Japanese Society for Hygiene 2013

\begin{abstract}
Objectives Burning of biomass fuel (cow-dung, crop residue, dried leaves, wood, etc.) in the kitchen releases smoke, which may impair the respiratory functions of women cooking there. This paper aimed to compare the respiratory symptoms between biomass fuel users and gas fuel users in Bangladesh.

Methods A cross-sectional survey was conducted through face-to-face interviews and chest examination of 224 adult women using biomass fuel in a rural village and 196 adult women using gas fuel in an urban area.

Results The prevalence of respiratory involvement (at least one among nine symptoms and two diseases) was significantly higher among biomass users than among gas users (29.9 vs. $11.2 \%)$. After adjustment for potential confounders by a logistic model, the odds ratio (OR) of the biomass users for the respiratory involvement was significantly higher $(\mathrm{OR}=3.23,95 \%$ confidence interval $1.30-8.01)$. The biomass fuel use elevated symptoms/diseases significantly; the adjusted OR was 3.04 for morning cough, 7.41 for nasal allergy, and 5.94 for chronic bronchitis. The mean peak expiratory flow rate of biomass users
\end{abstract}

Md. A. Alim $(\varangle) \cdot$ M. A. B. Sarker · Y. Yoshida .

N. Hamajima

Department of Healthcare Administration, Nagoya University

Graduate School of Medicine, 65 Tsurumai-cho, Showa-ku,

Nagoya 466-8550, Japan

e-mail: mralim2000@yahoo.com

Md. A. Alim · S. Selim

Directorate General of Health Services, Mohakhali, Dhaka

1212, Bangladesh

Md. R. Karim

Department of Epidemiology, National Institute of Preventive and Social Medicine, Mohakhali, Dhaka 1212, Bangladesh
(253.83 1/min) was significantly lower than that of gas users (282.37 1/min).

Conclusions The study shows significant association between biomass fuel use and respiratory involvement among rural women in Bangladesh, although the potential confounding of urban/rural residency could not be ruled out in the analysis. The use of smoke-free stoves and adequate ventilation along with health education to the rural population to increase awareness about the health effects of indoor biomass fuel use might have roles to prevent these involvements.

Keywords Biomass fuel · Gas fuel · Respiratory involvement $\cdot$ Women $\cdot$ Bangladesh

\section{Introduction}

Nearly one-third of the world's population and threequarters of rural households in developing countries still rely on unprocessed biomass fuel such as wood, cow-dung, and crop residues for cooking and heating [1]. Cooking and heating with such solid fuel is the major source of indoor air pollution (IAP), and the pollution levels exceed the standard allowable limits in developing countries [2]. According to the World Health Organization, IAP from burning of biomass fuel has emerged as one of the top ten global threats to public health, as it accounts for $2.7 \%$ of the global burden of disease. Especially for women and children, who spend most time indoors during cooking, the levels of exposure to polluted air are reported to be higher [3]. IAP is the second largest global environmental contributor to morbidity, and it causes 2.2-2.8 million deaths annually [4]. Polluted indoor air contains a range of healthdamaging pollutants, such as carbon monoxide (CO), 
carbon dioxide $\left(\mathrm{CO}_{2}\right)$, nitrogen dioxide $\left(\mathrm{NO}_{2}\right)$, sulfur dioxide $\left(\mathrm{SO}_{2}\right)$, volatile organic compounds (VOCs), and particulate matter [5-8]. These pollutants are able to cross the alveolar-capillary barrier and penetrate deep into the lungs [9].

A meta-analysis of 25 studies has reported associations between domestic use of solid biomass fuel (wood, dung, crop residue, etc.) and diverse respiratory diseases in rural populations [10]. The respiratory effects of chronic exposure to wood smoke and other forms of biomass for adults in developing countries increase the prevalence of chronic bronchitis [11-13], respiratory failure, and cor pulmonale $[13,14]$. Another meta-analysis of biomass smoke effects on chronic obstructive pulmonary disease (COPD) found that biomass smoke exposure elevated significantly the risk of COPD, compared to those not exposed to biomass smoke, especially among women [15]. A study conducted in Nepal showed that biomass smoke caused significantly more respiratory disorders than cleaner fuels did [16]. Several randomized control trials in rural Mexico have shown cleaner fuels were significantly associated with a reduction of respiratory symptoms among women [17]. A study in Pakistan found a strong association with chronic bronchitis in biomass-usingr women when compared with liquid petroleum (LP) gas-using women [18].

Almost all of these studies were conducted in rural areas while attempting to assess the respiratory health of women and children, and no study has compared cooking by women in rural versus urban settings. However, differences in the indoor air quality (IAQ) between urban and rural areas in developing countries can be bigger due to the gaps between the factors contributing to the IAQ of rural and urban areas, such as house and kitchen structure, ventilation, lifestyle, source of outdoor air pollutants, and population density [19]. Thus, understanding the respiratory involvement of smoke due to the combustion of biomass and gas fuel among women in both urban and rural areas in developing countries is one of the prioritized steps for taking countermeasures to prevent women's respiratory morbidity.

Almost two-thirds of the population of Bangladesh dwells in rural areas. Most of them have poor living conditions and almost all of them use poorly ventilated kitchens or cooking spaces [20]. About $94 \%$ of the rural people in Bangladesh use biomass in the form of wood, straw, leaf, and dried cow-dung as a cooking fuel, while only $4.5 \%$ use LP gas, $1 \%$ kerosene, and $0.3 \%$ use electricity [21]. Those sticking to their old tradition of cooking indoors on three-stone stoves, especially women, are at risk of developing respiratory diseases associated with biomass fuel. However, very little attention has been focused in Bangladesh on this important aspect of public health. Several studies conducted in rural and urban areas of Bangladesh have measured the concentrations of pollutants from the burning of biomass fuel in the kitchen and associations of respiratory involvements on children under 5 years old $[3,19,22]$.

To our knowledge, no studies have been conducted so far in the rural areas of Bangladesh on smoke exposure from biomass fuel combustion to the prevalence of respiratory diseases among women. It is imperative to ascertain the risk associated with exposure to biomass smoke and the development of diseases, particularly respiratory illness, on women in Bangladesh. The present study aimed to compare the respiratory symptoms/diseases prevalence among women exposed to biomass fuel smoke with those among women using gas fuel in Bangladesh.

\section{Materials and methods}

Study period and location

This was a cross-sectional study carried out in the summer season from April to June 2012 in two areas of Bogra, a northern district of Bangladesh. In the rural area (Madla union, approximately $5 \mathrm{~km}$ from Bogra city) there are 16 residential communities where people are generally in the poor or middle class and depend on biomass fuel for daily cooking and heating purposes. All of them cook indoors on traditional three-stone stoves. The urban area (Thanthania, $2 \mathrm{~km}$ from Bogra city) has six residential communities, where people are mostly in the middle class and depend upon LP gas for daily cooking and heating purposes. These places were selected, because there were no industries in the surrounding areas within a radius of $6 \mathrm{~km}$. Moreover, the numbers of motor vehicles in the sampling areas were negligible, as bicycles and three-wheeler rikshaws were the main form of transport. Thus, the areas were thought to be free from industrial pollution and with minimum vehicular emissions.

\section{Sampling}

In the 16 residential communities of the rural area, we randomly selected the 'Nandigram' community where the total households were 308 [23]. One who was involved in the daily cooking process for each household (in total 280 women) agreed to participate in our study. Among them, $224(80 \%)$ women who met the eligibility criteria were recruited. In the urban area, the 'Sha Para' community with 290 households was randomly selected from six residential communities [23]. Among 235 volunteer women, one from each household, 196 (83.4\%) women met the eligibility criteria. The eligibility criteria were: (1) women aged 15 years or older having regular or daily 
cooking practice for at least 3 years, (2) residents in the study area for at least one year, (3) never smokers, (4) non pregnant, and (5) without pulmonary tuberculosis.

\section{Data collection}

A structured questionnaire taken from the European Community Respiratory Health Survey (ECRHS) on chronic bronchitis conducted in developing countries [2426] was modified and adopted to this study after validation by local experts. The questionnaire was adapted to the local language using a forward- and back-translation procedure by a professional translator. The questionnaire was then pre-tested among 20 samples in a different place near the study area to ensure understandability, clarity of wording, and reliability. It was modified and finalized according to the feedback received from the pre-testing. The questionnaire was administered to the subjects by community female health staffs working in the study areas who had attended a 1-day training session including a role-play to demonstrate their proficiency. The questionnaire was on socio-demographic status, duration of cooking, type of fuel used for cooking in the household, house and kitchen infrastructure, history of passive smoking, respiratory diseases in family, and respiratory symptoms in the last 12 months. The respiratory involvement was defined as the presence of at least one respiratory symptom or disease. A clinical definition of chronic bronchitis useful in epidemiological studies was adopted, although this clinical definition might not exactly reflect the impact of airflow limitation on the morbidity and mortality in COPD patients. Chronic bronchitis is defined as cough and sputum production for at least 3 months and in each of two consecutive years [27].

Data were collected by face-to-face interviews of the respondents with the questionnaire. The time for interview was informed in advance and agreed upon so that sufficient time could be used for the interview. Their weight and height were measured. The peak expiratory flow rate (PEFR) was also measured in the standing position with a Wright Mini-Peak Flow Meter (Airmed; Clement Clarke International, London, UK). The subjects were asked to relax before taking the PEFR measurement. After adequate rest, subjects were instructed to take a deep breath and exhale as forcefully as possible in one single blow into the instrument. During breathing out into the instrument the nose was closed by a nose clip. The highest of three satisfactory measurements was recorded as the PEFR for the subject. For those who had taken an inhaler or oral bronchodilator on the day, the measurement was done on the next day. The PEFR was recorded nearest to $1 / \mathrm{min}$. Bronchial obstruction on the basis of PEFR\% (the observed
PEFR divided by the predicted PEFR for participants) was defined as: $70-80 \%$ was mild, $60-70 \%$ was moderate, and $<60 \%$ was severe [28]. The predictive value of PEFR for women was calculated by the formula: $\{[$ (height in meters $\times 3.72)+2.24]-($ age $\times 0.03)\} \times 60 \quad$ [29]. Every respondent was examined by a physician at the time of the interview.

Data analysis

Collected data were checked and entered in the computer program Statistical Package for the Social Science, version 20.0 (SPSS, Chicago, IL, USA). Information on the type of cooking fuel was used to categorize the women into two groups: women using biomass fuel and women using a gas fuel (LP gas). The Pearson Chi square test was used for tests of independence between the main explanatory variable (fuel type) and other variables. A $t$ test was used for continuous variables. Multivariate logistic regression analysis was conducted to estimate the odds ratio (OR) and $95 \%$ confidence interval $(\mathrm{CI})$ of respiratory symptoms and diseases. A two-tailed $p$ value $<0.05$ was considered as statistically significant.

\section{Ethical consideration}

Before collecting data, permission was obtained from the local Union Parishad Chairman and Health Administration (Civil Surgeon, and Upazila Health and Family Planning Officer) of the study area. This study was approved by the ethical committee of the Bangladesh Medical Research Council. All participants gave written (or thumb-printed) consent after being fully informed about the objectives and expected consequences of the study. Women found coughing with severe breathing problems were provided a free check-up and treatment at the local Medical College Hospital.

\section{Results}

Of the 420 women selected in the study, $224(53.3 \%)$ were from a rural area using biomass fuel and $196(46.7 \%)$ were from an urban area using LP gas for cooking purposes.

The biomass users were significantly older, less educated, and had less income with more family members than the gas users. A majority of the respondents were married in both biomass $(83.0 \%)$ and gas $(87.2 \%)$ groups. There was no significant difference in cooking hours/day between the groups, whereas the total years of cooking for biomass users was significantly longer than for gas users. Most $(97.4 \%)$ of the gas users' kitchens were separated from the 
Table 1 Characteristics of respondents

\begin{tabular}{|c|c|c|c|c|c|}
\hline \multirow[t]{2}{*}{ Characteristic } & \multicolumn{2}{|c|}{ Biomass users $^{\mathrm{a}}$} & \multicolumn{2}{|l|}{ Gas users $^{\mathrm{b}}$} & \multirow[t]{2}{*}{$p$ value } \\
\hline & $n(\%)$ & Mean $( \pm \mathrm{SD})$ & $n(\%)$ & Mean $( \pm \mathrm{SD})$ & \\
\hline Total & $224(100)$ & & $196(100)$ & & \\
\hline Age (years) & & $34.96( \pm 8.38)$ & & $30.13( \pm 7.58)$ & $<0.001$ \\
\hline $15-25$ & $37(16.5)$ & & $61(31.1)$ & & \\
\hline $26-35$ & $96(42.9)$ & & $102(52.0)$ & & \\
\hline $36-58$ & 91 (40.6) & & $33(16.8)$ & & \\
\hline Marital status & & & & & 0.228 \\
\hline Married & $186(83.0)$ & & $171(87.2)$ & & \\
\hline Single ${ }^{c}$ & $38(17.0)$ & & $25(12.8)$ & & \\
\hline Body mass index & & $21.35( \pm 2.86)$ & & $23.19( \pm 3.43)$ & $<0.001$ \\
\hline Education & & & & & $<0.001$ \\
\hline No education & $141(62.9)$ & & $0(0.0)$ & & \\
\hline Primary & $73(32.6)$ & & $24(12.2)$ & & \\
\hline Secondary and above & $10(4.5)$ & & $172(87.8)$ & & \\
\hline Family monthly income (US \$) & & $99( \pm 42)$ & & $177( \pm 58)$ & $<0.001$ \\
\hline$<65$ & $54(24.1)$ & & $0(0.0)$ & & \\
\hline $65-130$ & $117(52.2)$ & & $46(23.5)$ & & \\
\hline$>130$ & $53(23.7)$ & & $150(76.5)$ & & \\
\hline Total family members & & $6.22( \pm 1.84)$ & & $4.25( \pm 1.42)$ & $<0.001$ \\
\hline $1-4$ & $55(24.6)$ & & $139(70.9)$ & & \\
\hline$>4$ & $169(75.4)$ & & $57(29.1)$ & & \\
\hline Cooking hours/day & & $4.62( \pm 0.91)$ & & $4.60( \pm 0.87)$ & 0.872 \\
\hline $1-3$ & $25(11.2)$ & & $23(11.7)$ & & \\
\hline$>3$ & $199(88.8)$ & & $173(88.3)$ & & \\
\hline Total years of cooking & & $16.04( \pm 6.00)$ & & $9.38( \pm 2.96)$ & $<0.001$ \\
\hline Separate kitchen & & & & & $<0.001$ \\
\hline Yes & $175(78.1)$ & & $191(97.4)$ & & \\
\hline No & 49 (21.9) & & $5(2.6)$ & & \\
\hline Kitchen type & & & & & $<0.001$ \\
\hline Closed without ventilation & $74(33.0)$ & & $28(14.3)$ & & \\
\hline Partially closed & $102(45.5)$ & & $47(24.0)$ & & \\
\hline Open & $46(20.5)$ & & $0(0.0)$ & & \\
\hline Closed with ventilation & $2(0.9)$ & & $121(61.7)$ & & \\
\hline House type & & & & & $<0.001$ \\
\hline Cement & $18(8.0)$ & & $155(79.1)$ & & \\
\hline Semi cement & $94(42.0)$ & & $41(20.9)$ & & \\
\hline Thatched & $112(50.0)$ & & $0(0.0)$ & & \\
\hline Passive smoking & & & & & 0.400 \\
\hline Yes & $57(25.4)$ & & $43(21.9)$ & & \\
\hline No & $167(74.6)$ & & $153(78.1)$ & & \\
\hline Respiratory disease in family & & & & & 0.756 \\
\hline Yes & $19(8.5)$ & & $15(7.7)$ & & \\
\hline No & $205(91.5)$ & & $181(92.3)$ & & \\
\hline
\end{tabular}

A $t$ test was used to compare means

$S D$ standard deviation

${ }^{a}$ Biomass fuel users were sampled in a rural area, Madla; cow-dung $49.1 \%$, crops residues $30.8 \%$, dry leaves $14.3 \%$, and wood $5.8 \%$

${ }^{b}$ Gas fuel users were sampled in an urban area, Thanthania

c Single includes never married, separated, or widowed 
Fig. 1 Prevalence of respiratory involvement according to fuel used of the participants. Prevalence of respiratory involvement was $28.2 \%$ for cow-dung users, $33.3 \%$ crops residue users, $28.1 \%$ dry leaves users, $30.8 \%$ wood users, and $11.2 \%$ LP gas users

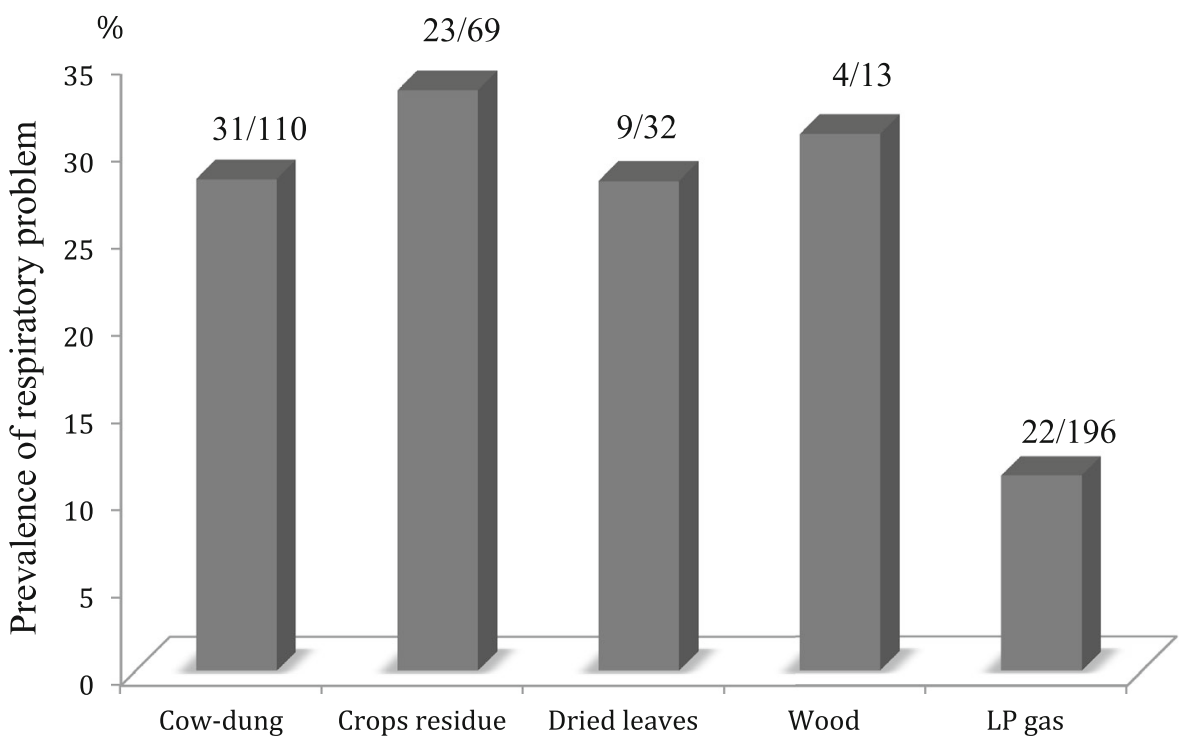

Types of fuel

Table 2 Odds ratio (OR) of biomass users for respiratory symptoms, respiratory diseases and severe bronchial obstruction based on PEFR

\begin{tabular}{|c|c|c|c|c|c|c|}
\hline \multirow[t]{2}{*}{ Symptoms/disease } & \multirow{2}{*}{$\begin{array}{l}\text { Biomass users } \\
(n=224) \\
n(\%)\end{array}$} & \multirow{2}{*}{$\begin{array}{l}\text { Gas users }^{\mathrm{a}} \\
(n=196) \\
n(\%)\end{array}$} & \multicolumn{2}{|l|}{ Crude OR } & \multicolumn{2}{|l|}{ Adjusted $\mathrm{OR}^{\mathrm{b}}$} \\
\hline & & & OR $(95 \% \mathrm{CI})$ & $p$ value & OR $(95 \% \mathrm{CI})$ & $p$ value \\
\hline $\begin{array}{l}\text { Respiratory involvement with at least one } \\
\text { symptom/disease }\end{array}$ & $67(29.9)$ & $22(11.2)$ & $3.38(1.99-5.72)$ & $<0.001$ & $3.23(1.30-8.01)$ & 0.011 \\
\hline Morning cough & $52(23.2)$ & $15(7.7)$ & $3.65(1.98-6.72)$ & $<0.001$ & $3.04(1.11-8.35)$ & 0.031 \\
\hline Chest tightness & $34(15.2)$ & $8(4.1)$ & $4.21(1.90-9.32)$ & $<0.001$ & $3.47(1.00-12.07)$ & 0.051 \\
\hline Wheezing with dyspnea & $33(14.7)$ & $9(4.6)$ & $3.59(1.67-7.71)$ & 0.001 & $2.11(0.60-7.51)$ & 0.248 \\
\hline Wheezing & $32(14.3)$ & $11(5.6)$ & $2.80(1.37-5.73)$ & 0.005 & $2.58(0.79-8.44)$ & 0.117 \\
\hline Nasal allergy & $27(12.1)$ & $6(3.1)$ & $4.34(1.75-10.75)$ & 0.002 & $7.41(2.03-27.08)$ & 0.002 \\
\hline Wheezing in the past & $22(9.8)$ & $11(5.6)$ & $1.83(0.87-3.88)$ & 0.114 & $1.00(0.23-4.07)$ & 0.998 \\
\hline Wheeze without cold & $13(5.8)$ & $8(4.1)$ & $1.45(0.59-3.57)$ & 0.421 & $2.89(0.67-12.54)$ & 0.156 \\
\hline Woken by coughing attacks & $20(8.9)$ & $6(3.1)$ & $3.11(1.22-7.90)$ & 0.017 & $1.87(0.39-9.02)$ & 0.433 \\
\hline Woken by chest tightness & $10(4.5)$ & $5(2.6)$ & $1.79(0.60-5.32)$ & 0.298 & $2.70(0.47-15.71)$ & 0.268 \\
\hline Chronic bronchitis diagnosed by physician & $15(6.7)$ & $3(1.5)$ & $4.62(1.32-16.20)$ & 0.017 & $5.94(1.02-34.45)$ & 0.047 \\
\hline Asthma diagnosed by physician & $13(5.8)$ & $3(1.5)$ & $3.96(1.11-14.12)$ & 0.034 & $3.42(0.50-23.59)$ & 0.212 \\
\hline $\begin{array}{l}\text { Severe bronchial obstruction based on } \mathrm{PEFR}^{\mathrm{c}} \\
(<60 \% \text { predicted value })\end{array}$ & $124(55.4)$ & $57(29.1)$ & $3.02(2.02-4.54)$ & $<0.001$ & $4.54(2.10-9.82)$ & $<0.001$ \\
\hline
\end{tabular}

$95 \%$ CI $95 \%$ confidence interval

${ }^{a}$ Reference group

b Adjusted for age, education, cooking hours/day, and separate kitchen

c PEFR peak expiratory flow rate

living room, while for biomass users this was $78.1 \%$. The socio-demographic characteristics and other variables of the participants are summarized in Table 1 .

There was no significant difference in respiratory involvement prevalence among the different types of biomass fuel users (Fig. 1). As Table 2 shows, any frequency was higher among the biomass users than among the gas users, especially respiratory involvement (29.9 vs. $11.2 \%$ ), morning cough (23.2 vs. $7.7 \%)$, chest tightness (15.2 vs. $4.1 \%$ ), wheezing with dyspnea (14.7 vs. $4.6 \%$ ), wheezing (14.3 vs. $5.6 \%$ ), nasal allergy (12.1 vs. $3.1 \%$ ), woken by coughing attacks ( 8.9 vs. $3.1 \%$ ), chronic bronchitis (6.7 vs. 
Table 3 Number of subjects with respiratory involvement and odds ratio (OR) according to subgroup

\begin{tabular}{|c|c|c|c|c|c|c|}
\hline \multirow[t]{2}{*}{ Characteristic } & \multirow{2}{*}{$\begin{array}{l}\text { Biomass users with respiratory } \\
\text { involvement, } n(\%)\end{array}$} & \multirow{2}{*}{$\begin{array}{l}\text { Gas users }{ }^{\mathrm{a}} \text { with respiratory } \\
\text { involvement, } n(\%)\end{array}$} & \multicolumn{2}{|l|}{ Crude OR } & \multicolumn{2}{|l|}{ Adjusted $\mathrm{OR}^{\mathrm{b}}$} \\
\hline & & & OR $(95 \% \mathrm{CI})$ & $p$ value & OR $(95 \% \mathrm{CI})$ & $p$ value \\
\hline \multicolumn{7}{|l|}{ Age in years } \\
\hline $15-25$ & 6/37 (16.2) & 1/61 (1.6) & $11.61(1.34-100.79)$ & 0.026 & $2.03(0.05-82.76)$ & 0.708 \\
\hline $26-35$ & $35 / 96(36.5)$ & 17/102 (16.7) & $2.87(1.47-5.59)$ & 0.002 & $3.46(1.01-11.85)$ & 0.048 \\
\hline $36-58$ & 26/91 (28.6) & $4 / 33(12.1)$ & $2.90(0.93-9.07)$ & 0.067 & $6.90(1.23-38.89)$ & 0.029 \\
\hline \multicolumn{7}{|l|}{ Education } \\
\hline No education & 39/141 (27.7) & 0/0 (0.0) & - & - & - & - \\
\hline Primary & 26/73 (35.6) & $3 / 24(12.5)$ & $3.87(1.05-14.23)$ & 0.041 & $2.96(0.74-11.78)$ & 0.125 \\
\hline Secondary and above & $2 / 10(20.0)$ & 19/172 (11.0) & $2.01(0.40-10.19)$ & 0.398 & $1.51(0.28-8.01)$ & 0.629 \\
\hline \multicolumn{7}{|l|}{ Cooking hours/day } \\
\hline $1-3$ & $0 / 25(0.0)$ & $2 / 23(8.7)$ & 0.00 & - & 0.00 & - \\
\hline$>3$ & 67/199 (33.7) & 20/173 (11.6) & $3.89(2.24-6.74)$ & $<0.001$ & $3.67(1.45-9.29)$ & 0.006 \\
\hline \multicolumn{7}{|l|}{ Separate kitchen } \\
\hline Yes & $42 / 175(24.0)$ & 22/191 (11.5) & $2.43(1.38-4.26)$ & 0.002 & $2.49(0.93-6.63)$ & 0.068 \\
\hline No & 25/49 (51.0) & $0 / 5(0.0)$ & $\infty$ & - & $\infty$ & - \\
\hline
\end{tabular}

$95 \%$ CI $95 \%$ confidence interval

${ }^{\text {a }}$ Reference group

${ }^{\mathrm{b}}$ OR adjusted for age, education, cooking hours/day, and separate kitchen

$1.5 \%$ ), and asthma diagnosed by physician (5.8 vs. $1.5 \%$ ). After adjusting for potential confounders, multivariate logistic regression analysis revealed that the use of biomass fuel was significantly associated with the following symptoms and diseases: respiratory involvement with at least one symptom/disease $(\mathrm{OR}=3.23 ; p=0.011)$, morning cough $(\mathrm{OR}=3.04 ; p=0.031)$, nasal allergy $(\mathrm{OR}=7.41 ; \quad p=0.002), \quad$ and chronic bronchitis $(\mathrm{OR}=5.94 ; p=0.047)$. We also found a significant association between severe bronchial obstruction based on PEFR\% and biomass use. Based on PEFR\%, bronchial obstruction in the biomass users was $12.9 \%$ mild, $31.2 \%$ moderate, and $55.4 \%$ severe, while in the gas users it was 28.6, 37.8, and $29.1 \%$, respectively. The OR for the severe bronchial obstruction based on PEFR \% was 4.54 $(p<0.001)$. The mean $( \pm \mathrm{SD})$ of PEFR was 253.83 $( \pm 29.04) \mathrm{l} / \mathrm{min}$ for biomass users and $282.37( \pm 32.50) \mathrm{l} /$ min for gas users. The difference was significant $(p<0.001)$.

In regression models adjusted by age, education, cooking hours/day, and separate kitchen (Table 3), women aged $36-58$ years exposed to biomass fuel were found to have a significantly higher association with respiratory involvement than younger women; the ORs of respiratory involvement among the age groups 15-25, 26-35, and 36-58 years were 2.03, 3.46, and 6.90, respectively. The difference in the ORs was not clear for education, and non-evaluable for cooking hours and separate kitchen.

\section{Discussion}

This study documented the higher prevalence of respiratory involvement among women using biomass fuel (29.9\%) than among those using gas fuel $(11.2 \%)$ in Bangladesh. The adjusted OR of respiratory involvement was highest among women aged $36-58$ years.

The observed higher odds (3.23) for respiratory involvement is consistent with the results of several other studies conducted in Mexico, Nigeria, and Turkey [30-32]. A case-control study conducted in Bogota, Columbia, found a significant association between biomass smoke and obstructed airway disease (OAD) [33]. We found $6.7 \%$ chronic bronchitis and $5.8 \%$ asthma among rural biomass users, which are similar to a study in Pakistan [18]. Meanwhile, another study in Turkey found chronic bronchitis symptoms as high as $58.9 \%$ and asthma-like symptoms at $63.3 \%$ among biomass fuel-using females [34]. The possible reasons for such a high prevalence of symptoms in Uzun's study were longer exposure to biomass fuel and prevalent smoking habit $(33 \%)$. Several studies have reported that tobacco use or smoking and biomass smoke for cooking were associated with OAD and overall respiratory symptoms $[26,33,35]$.

Due to poverty as well as lack of knowledge about the risk of biomass fuel use, women are continuously using such low-quality fuels, because they are most accessible sources of energy available in rural Bangladesh. Gas is not widely used because of the cost and unavailability of 
supply, which has been a problem for more than a decade. It can be assumed that the socio-economic factors of biomass fuel users played a role in our study subjects, since the majority of the participating women had no education and a low monthly income. The role of socio-economic status for determining the type of cooking fuel used in the kitchen has been described in other studies in developing countries [36-38]. According to another study in developing countries, individuals tend to use cleaner fuels as socioeconomic conditions improve [39].

The present study also revealed that different kinds of respiratory symptoms (morning cough, chronic bronchitis, nasal allergy) were 3.04-7.41 times significantly more likely to be reported in biomass fuel users than in gas fuel users, which supports those of other studies [11, 18, 25, 26, 30, 35]. Other respiratory symptoms (chest tightness, wheezing, wheezing with dyspnea, wheezing in the past, wheezing without cold, woken by coughing attacks, woken by chest tightness) were found to be higher with the use of biomass fuel, although these were not significant. The increased frequency of respiratory symptoms or diseases can be attributed to toxic substances released during the combustion of biomass fuel. The inefficient burning of biomass fuel, in traditional stoves, generates large amounts of particulate matter, $\mathrm{CO}$, hydrocarbons, organic oxygen compounds, free radicals, and chlorinated organic compounds [40]. These toxic substances may impair respiratory functions by reducing mucociliary clearance, alveolar macrophage response, and optimal local immunity [39].

Our analyses demonstrated that older women using biomass fuel were significantly more associated with respiratory involvements than younger. Women aged 26-35 years were 3.46 times and women aged $36-58$ years were 6.90 times more likely to have respiratory involvement than the 15-25 years age group. Similarly, another study reported that individuals aged $>40$ years had 4.3 times more chance to develop respiratory involvement than the younger age group [11]. We speculate that the reason might be due to an increase in the total years of cooking for the older groups, which causes women's prolong exposure to cooking smoke. The risk of Mexican older females ( $>40$ years) for chronic bronchitis alone and chronic bronchitis with OAD increased linearly with the increase in hour-years of cooking with a wood stove. ORs for exposure to $>200$ h-years compared with non-exposure were 15.0 for chronic bronchitis only and 75.0 for chronic bronchitis with OAD [41]. A Colombian study also found a higher risk of COPD among those who were exposed to biomass smoke for $>10$ years [42]. Another observation of our study was that women who cooked $>3 \mathrm{~h} /$ day with biomass fuel had a strong association with respiratory involvements. Pandey [12] documented a significant increase in the prevalence of chronic bronchitis among women with the increase of time they spent per day near a kitchen in Nepal. Another study in western Sierra Leone found higher acute respiratory infection prevalence among those who spent more time in kitchens with wood stoves [43].

Our findings should be viewed in the context of several limitations. First, the study was unable to measure indoor emissions, indoor concentrations, and amount of smoke exposure by individual. Second, because of constraints of time and budget, the sample size was relatively small, so the results cannot be generalized to the whole country. Third, this study did not ascertain the outdoor concentrations of pollutants, which would give an idea about the impact of outdoor air on indoor air quality, although this was minimized by the fact that the study areas were free from industrial pollution with less vehicular emission. Fourth, we could not measure lung function tests except PEFR. Fifth, due to the cross-sectional nature of the study, it was impossible to interpret properly the causal relations of the involvements. Sixth, the wall materials of house/ kitchen may affect the respiratory health of women. Unfortunately we did not check this issue through our study. Finally, the other potential confounding of urban/ rural residency was not adjusted, because all biomass users were sampled from the rural area and all gas users from the urban area. However, we maintained a standard procedure to measure PEFR; and we applied a standard case definition to detect chronic bronchitis. Moreover, the study represents the first study to understand the impact of cooking smoke from biomass and gas fuel on women's respiratory health in Bangladesh. Further studies should be conducted, including arterial blood gas analysis and lung function tests to construct and evaluate different scientific, low-cost cooking maneuvers in reducing cooking smoke exposure among the rural women in Bangladesh.

In conclusion, our results suggest that there was a significant association between women using biomass fuel and respiratory involvements, although the other potential confounding of urban/rural residency could not be ruled out in the analysis. From a public health perspective, it is important to control possible risks on the health of rural women. By considering the fact that rural women are potentially exposed to the smoke of biomass fuel, government should deal with this topic seriously. The use of smoke-free stoves and adequate ventilation might have roles to prevent these respiratory symptoms/diseases. In addition, our study underscores the need for health education to the rural population to increase awareness about the health effects of indoor biomass cooking smoke. The government should also assist the population in shifting to cleaner fuels by ensuring a constant supply of gas in rural area at a price the poor people can afford. 
Acknowledgments We greatly extend our sincere thanks to the community female health staffs of Bogra district who helped to collect data. We are also grateful to local health authorities who gave permission to conduct this study and to all the respondents for their hospitality and cooperation.

Conflict of interest The authors declare no conflict of interests.

\section{References}

1. Ochieng CA, Vardoulakis S, Tonne C. Are rocket mud stoves associated with lower indoor carbon monoxide and personal exposure in rural Kenya? Indoor Air. 2013;23:14-24.

2. World Health Organization (WHO)/United Nations Development Programme (UNDP) Joint statement. Indoor air pollution-the killer in the kitchen. Geneva: WHO/UNDP; 2004.

3. Khalequzzaman M, Kamijima M, Sakai K, Hoque BA, Nakajima $\mathrm{T}$. Indoor air pollution and the health of children in biomass- and fossil-fuel users of Bangladesh: situation in two different seasons. Environ Health Prev Med. 2010;15:236-43.

4. Rinne ST, Rodas EJ, Bender BS, Rinne ML, Simpson JM, GalerUnti R, et al. Relationship of pulmonary function among women and children to indoor air pollution from biomass use in rural Ecuador. Resp Med. 2006;100:1208-15.

5. Kim KH, Jahan SA, Kabir E. A review of diseases associated with household air pollution due to the use of biomass fuels. J Hazard Mater. 2011;192:425-31.

6. Zhang J, Smith KR. Emissions of carbonyl compounds from various cook stoves in China. Environ Sci Technol. 1999;33:2311-20.

7. Smith KR, Samet JM, Romieu I, Bruce N. Indoor air pollution in developing countries and acute respiratory infections in children. Thorax. 2000;55:518-32.

8. Jan AJS. Risk assessment of acute health and comfort effects of indoor air pollution. Ann N Y Acad Sci. 1992;641:56-62.

9. Tesfaigzi Y, Singh SP, Foster JE, Kubatko J, Barr EB, Fine PM, et al. Health effects of sub chronic exposure to low levels of wood smoke in rats. Toxicol Sci. 2002;65:115-25.

10. Po JY, FitzGerald JM, Carlsten C. Respiratory disease associated with solid biomass fuel exposure in rural women and children: systematic review and meta-analysis. Thorax. 2011;66:232-9.

11. Albalak R, Frisancho AR, Keeler GJ. Domestic biomass fuel combustion and chronic bronchitis in two rural Bolivian villages. Thorax. 1999;54:1004-8.

12. Pandey MR. Domestic smoke pollution and chronic bronchitis in a rural community of the hill region of Nepal. Thorax. 1984;39:337-9.

13. Pandey MR, Basnyat N, Neupane R. Chronic bronchitis and chronic cor pulmonale in Nepal: a scientific epidemiologic study. Kathmandu: Mrigendra Samjhana Medical Trust; 1988.

14. Sandoval J, Salas J, Martinez-Guerra ML, Gomez A, Martinez C, Portales A, et al. Pulmonary arterial hypertension and cor pulmonale associated with chronic domestic wood smoke inhalation. Chest. 1993;103:12-20.

15. Hu G, Zhou Y, Tian J, Yao W, Li J, Li B, et al. Risk of COPD from exposure to biomass smoke: a meta-analysis. Chest. 2010;138:20-31.

16. Shrestha IL, Shrestha SL. Indoor air pollution from biomass fuels and respiratory health of the exposed population in Nepalese households. Int J Occup Environ Health. 2005;11:150-60.

17. Romieu I, Riojas-Rodriguez H, Marron-Mares AT, Schilmann A, Perez-Padilla R, Masera O. Improved biomass stove intervention in rural Mexico: impact on the respiratory health of women. Int J Respir Crit Care Med. 2009;180:649-56.

18. Akhtar T, Ullah Z, Khan MH, Nazli R. Chronic bronchitis in women using solid biomass fuel in rural Peshawar, Pakistan. Chest. 2007;132:1472-5.

19. Khalequzzaman M, Kamijima M, Sakai K, Ebara T, Hoque BA, Nakajima T. Indoor air pollution and health of children in biomass fuel-using households of Bangladesh: comparison between urban and rural areas. Environ Health Prev Med. 2011;16:375-83.

20. Bangladesh Bureau of Statistics (BBS). Household Income and Expenditure Survey (HIES)—2010, Dhaka; 2011.

21. Bangladesh Bureau of Statistics (BBS). Bangladesh Socio-economic and Demographic Report 2011, Dhaka; 2012.

22. Khalequzzaman M, Kamijima M, Sakai K, Chowdhury NA, Hamajima N, Nakajima T. Indoor air pollution and its impact on children under five years old in Bangladesh. Indoor Air. 2007; 17:297-304.

23. Bangladesh Bureau of Statistics (BBS). Bangladesh Population and Housing Census 2011. Dhaka, Bangladesh; 2012.

24. Burney PG, Luczynska C, Chinn S, Jarvis D. The European Community Respiratory Health Survey. Eur Respir J. 1994;7:954-60.

25. Menezes AM, Victora CG, Rigatto M. Prevalence and risk factors for chronic bronchitis in Pelotas, RS, Brazil: a population-based study. Thorax. 1994;49:1217-21.

26. Cetinkaya F, Gülmez I, Aydin T, Oztürk Y, Ozesmi M, Demir R. Prevalence of chronic bronchitis and associated risk factors in a rural area of Kayseri, Central Anatolia, Turkey. Monaldi Arch Chest Dis. 2000;55:189-93.

27. GOLD - Global Initiative for Chronic Obstructive Lung Disease [homepage on the Internet]. Global Strategy for the Diagnosis, Management, and Prevention of Chronic Obstructive Pulmonary Disease—updated 2013. http://www.goldcopd.org/ (Accessed 15 April 2013).

28. Kesavachandran C, Rastogi SK, Mathur N, Bihari V, Singh A. A study of the prevalence of respiratory morbidity and ventilatory obstruction in beauty parlour workers. Indian J Occup Environ Med. 2006;10:28-31.

29. Knudson RJ, Lebowitz MD, Holberg CJ, Burrows B. Changes in the normal maximal expiratory flow-volume curve with growth and aging. Am Rev Respir Dis. 1983;127:725-34.

30. Regalado J, Perez-Padilla R, Sansores R, Páramo Ramirez JI, Brauer M, Pare' $\mathrm{P}$, et al. The effect of biomass burning on respiratory symptoms and lung function in rural Mexican women. Am J Respir Crit Care Med. 2006;74:901-5.

31. Desalu OO, Adekoya AO, Ampitan BA. Increased risk of respiratory symptoms and chronic bronchitis in women using biomass fuels in Nigeria. J Bras Pneumol. 2010;36:441-6.

32. Gül H, Gaga EO, Döğeroğlu T, Özden Ö, Ayvaz Ö, Özel S, et al. Respiratory health symptoms among students exposed to different levels of air pollution in a Turkish city. Int J Environ Res Public Health. 2011;8:1110-25.

33. Dennis RJ, Maldonado D, Norman S, Baena E, Martinez G. Wood smoke exposure and risk for obstructive airways disease among women. Chest. 1996;109:115-9.

34. Uzun K, Ozbay B, Ceylan E, Gencer M, Zehir I. Prevalence of chronic bronchitis-asthma symptoms in biomass fuel exposed females. Environ Health Prev Med. 2003;8:13-7.

35. Behera D, Jindal SK. Respiratory symptoms in Indian women using domestic cooking fuels. Chest. 1991;100:385-8.

36. Gupta S, Ravindranath NH. Financial analysis of cooking energy options for India. Energy Convers Manage. 1997;38:1869-76.

37. Ouedraogo B. Household energy preferences for cooking in urban Ouagadougou, Burkina Faso. Energy Policy. 2006;34:3787-95. 
38. Boadi KO, Kuitunen M. Factors affecting the choice of cooking fuel, cooking place and respiratory health in the Accra metropolitan area, Ghana. J Biosoc Sci. 2006;38:403-12.

39. Bruce N, Perez-Padilla R, Albalak R. Indoor air pollution in developing countries: a major environmental and public health challenge. Bull WHO. 2000;78:1078-92.

40. Naeher LP, Brauer M, Lipsett M, Zelikoff JT, Simpson CD, Koenig JQ, et al. Wood smoke health effects: a review. Inhal Toxicol. 2007;19:67-106.

41. Perez-Padilla R, Regalado J, Vedal S, Pare P, Chapela R, Sansores R, et al. Exposure to biomass smoke and chronic airway disease in Mexican women: a case-control study. Am J Respir Crit Care Med. 1996;154:701-6.

42. Caballero A, Torres-Duque CA, Jaramillo C, Bolívar F, Sanabria $\mathrm{F}$, Osorio $\mathrm{P}$, et al. Prevalence of COPD in five Colombian cities situated at low, medium, and high altitude. Chest. 2008; 133:343-9.

43. Taylor ET, Nakai S. Prevalence of acute respiratory infections in women and children in western Sierra Leone due to smoke from wood and charcoal stoves. Int J Environ Res Public Health. 2012;9:2252-65. 